Neural Correlates of Promotion and Prevention Goal Activation: An fMRI Study using an Idiographic Approach

By: Kari M. Eddington, Florin Dolcos, Roberto Cabeza, K. Ranga R. Krishnan, Timothy J. Strauman

Eddington, K., Dolcos, F., Cabeza, R., Krishnan, K.R., T Strauman, T. (2007). Neural correlates of promotion and prevention goal activation: an fMRI study using an idiographic approach. Journal of Cognitive Neuroscience, 19 (7), 1152-1162.

Made available courtesy of Massachusetts Institute of Technology (MIT) Press: http://www.mitpressjournals.org/loi/jocn

***(C) MIT Press. Reprinted with permission. No further reproduction is authorized without written permission from MIT Press. ***

Keywords: Goals | Social Perception | Motivation | Biotransformation | Self-regulation| Behavioral Assessment

***Note: Full text of article below 


\title{
Neural Correlates of Promotion and Prevention Goal Activation: An fMRI Study using an Idiographic Approach
}

\author{
Kari M. Eddington, Florin Dolcos, Roberto Cabeza, \\ K. Ranga R. Krishnan, and Timothy J. Strauman
}

\begin{abstract}
Regulatory focus theory [Higgins, E. T. Beyond pleasure and pain. American Psychologist, 52, 1280-1300, 1997] postulates two social-cognitive motivational systems, the promotion and prevention systems, for self-regulation of goal pursuit. However, the neural substrates of promotion and prevention goal activation remain unclear. Drawing on several literatures, we hypothesized that priming promotion versus prevention goals would activate areas in the left versus right prefrontal cortex (PFC), respectively, and that activation in these areas would be correlated with individual differences in chronic regulatory focus. Sixteen participants underwent functional
\end{abstract}

\section{INTRODUCTION}

Behavioral differences among people can be understood as reflecting differences in the kinds of goals they pursue and their characteristic ways of pursuing them. In an influential review, Austin and Vancouver (1996) conceptualized goals as internal representations of desired states and identified approach and avoidance goals as among the most important classes of goals. Goal representations are central to social-cognitive theories of self-regulation, defined as the processes by which individuals identify desired/undesired end-states, select and pursue means to attain/avoid them, and assess their progress (Carver \& Scheier, 1998).

Self-regulation occurs both intentionally, as when individuals explicitly choose goals and/or evaluate their progress toward them, and unintentionally or implicitly, as when goal representations are activated by features of the social context and influence subsequent behavior (Karoly, 1993). Self-regulation is thought to be ubiquitous in social cognition (Smith \& Semin, 2004; Andersen \& Chen, 2002). However, few studies have tested whether goal-related cognition can be discriminated from

Duke University magnetic resonance imaging while engaged in a depth-ofprocessing task, during which they were exposed incidentally to their own promotion and prevention goals. Task-related cortical activation was consistent with previous studies. At the same time, incidental priming of promotion goals was associated with left orbital PFC activation, and activation in this area was stronger for individuals with a chronic promotion focus. Findings regarding prevention goal priming were not consistent with predictions. The data illustrate the centrality of selfregulation and personal goal pursuit within the multilayered process of social cognition. other types of social cognition. Functional neuroimaging techniques could be particularly helpful in this regard.

Regulatory focus theory (RFT; Higgins, 1997) proposes that self-regulation involves two separate socialcognitive systems, each of which serves a distinct survival function. The promotion system regulates toward positive end-states by engaging strategic (as opposed to spatio-temporal) approach, that is, pursuing promotion goals involves attaining positive outcomes by "making good things happen." The promotion system is particularly active in the pursuit of aspirations, advancement, and accomplishments-what self-discrepancy theory (Higgins, 1987) calls "ideals." In contrast, the prevention system regulates toward positive end-states by engaging strategic avoidance; that is, pursuing prevention goals involves attaining positive outcomes by "keeping bad things from happening." The prevention system is particularly active in pursuit of responsibilities, duties, and obligations - what self-discrepancy theory calls "oughts." In signal detection terms (Tanner \& Swets, 1954), individuals with a chronic or situationally induced promotion regulatory focus are motivated to ensure "hits" (gains) and to ensure against errors of omission or "misses" (nongains). Individuals with a chronic or situationally induced prevention regulatory focus are motivated to ensure "correct rejections" (nonlosses) 
and to ensure against errors of commission or "false alarms" (losses). There is extensive support for the constructs of promotion and prevention, both as induced by situational features and as chronic individual differences (see Higgins \& Spiegel, 2004, for a review).

One distinguishing feature of social-cognitive theories of motivation is the assumption that self-regulation is a continuous process embedded within the complex, multilayered ongoing stream of social cognition (Higgins, 1990). This assumption implies that cognitive processes associated with promotion and prevention system activity should be detectable even when individuals are occupied with other tasks. At the brain level, patterns of neural activation in response to goal-relevant stimuli should be detectable even when promotion or prevention focus is engaged implicitly, for instance, by incidental priming of personal goals while individuals are performing some other behavior (which may or may not be self-referential in nature).

The promotion and prevention systems are related to, and yet distinguishable from, two biobehavioral motivational systems: the behavioral activation system (BAS; Gray, 1990; Depue \& Iacono, 1989; Fowles, 1988) and the behavioral inhibition system (BIS; Fowles, 1988; Gray, 1982). BAS and BIS are temperament-based brainbehavior systems that mediate spatio-temporal approach and avoidance behaviors, respectively (Depue \& Collins, 1999; Watson, Wiese, Vaidya, \& Tellegen, 1999; Carver \& White, 1994; Fowles, 1994). With origins in the animal behavior literature, the concepts of BIS and BAS have been applied to humans to characterize aversive and appetitive motivation, respectively, and the motivational and affective correlates thereof. However, current models of BIS and BAS do not incorporate the higher-order, abstract cognitive aspects of human goal pursuit emphasized in social-cognitive approaches to self-regulation (Strauman, 2002; Depue \& Collins, 1999; Tomarken \& Keener, 1998). RFT and related social-cognitive models of motivation (e.g., Mischel, 1990; Bandura, 1986) emphasize knowledge structures such as goal representations as primary determinants of momentary as well as chronic approach/avoidance tendencies (Cervone, 2000). The relation between the constructs of promotion/ prevention and BAS/BIS has yet to be clarified. Functional neuroimaging techniques may be particularly useful in determining whether the two sets of constructs are redundant, correlated but distinct, or orthogonal.

Prior research has found distinct patterns of brain activation linked to individual differences in BIS and BAS sensitivities. Resting electroencephalogram (EEG) and positron emission tomography (PET) studies have shown an association between BAS sensitivity and greater relative left frontal cortical activation, and, less consistently, between BIS sensitivity and greater relative right frontal cortical activation (e.g., Coan \& Allen, 2003; Harmon-Jones \& Allen, 1997; Sutton \& Davidson, 1997). This pattern of hemispheric asymmetry has been shown to discriminate between approach-related and avoidancerelated affective states (Davidson \& Irwin, 1999) and between processing of emotionally salient positive and negative stimuli (Dolcos, LaBar, \& Cabeza, 2004; Canli, Desmond, Zhao, Glover, \& Gabrieli, 1998). Those same regions have been implicated in goal-related cognition (Depue \& Collins, 1999; Tomarken \& Keener, 1998), suggesting the possibility that promotion/prevention and BAS/BIS may share neural substrates.

We found only two reports of associations between regulatory focus and patterns of brain activity. Amodio, Shah, Sigelman, Brazy, and Harmon-Jones (2004) observed greater relative left versus right resting EEG activation in association with individual differences in promotion versus prevention orientation, respectively. Cunningham, Raye, and Johnson (2005) examined the relationship between a four-item measure of regulatory focus and evaluative judgments of generic stimuli during functional magnetic resonance imaging (fMRI) scanning. They observed that promotion focus was associated with greater activity in the amygdala, anterior cingulate, and extrastriate cortex following positive stimuli when judging whether stimuli were good/bad (but not abstract/concrete). The same pattern of brain activity was associated with prevention focus following good/bad judgments of negative stimuli.

To our knowledge, no study has investigated the neural correlates of promotion or prevention goal activation or examined whether such activation is related to patterns found in the aforementioned studies of BAS/ BIS and regulatory focus. Given the idiographic nature of personal goals, it is important to determine whether classes of goals are associated reliably with particular patterns of brain activation even as the specific content of the goals varies from one individual to another. In addition, given the postulated ubiquitous role of selfregulation within social cognition, it also is important to determine whether neurobiological "signatures" of promotion or prevention goal activation can be observed even while individuals are engaged in pursuing a different goal (e.g., meeting the demands of an experimental task).

Despite the scarcity of research examining neural correlates of regulatory focus, there are bases for predicting which brain regions are likely to be associated with activation of promotion and prevention goals, respectively. As noted above, Amodio et al. (2004) found the same frontal asymmetry associated with individual differences in regulatory focus as had previously been found for individual differences in BAS/BIS strength as well as for dispositional positive/negative affectivity (Allen \& Kline, 2004; Davidson, 2004). These findings, along with the similarities between goal-directed behaviors mediated by BAS/BIS respectively and behavioral consequences of promotion/prevention goal activation, suggested that priming promotion goals would lead to left frontal activation, whereas priming prevention goals 
would lead to right frontal activation. Another basis for predicting the neural substrates of promotion and prevention goals comes from recent research on the anterior prefrontal cortex (aPFC), one of the least wellunderstood regions of the human brain (Miller \& Cohen, 2001). Reviewing both neuroanatomical and functional imaging studies, Ramnani and Owen (2004) proposed a specific, unique role for the aPFC and related regions of the orbital PFC consisting of integrating outcomes across separate cognitive operations in the pursuit of more abstract, higher-order goals. Given the evidence that individual differences in regulatory focus have a broad influence on memory, judgment, and decision making, as well as costs and benefits in interpersonal relations (Higgins \& Spiegel, 2004), the aPFC and associated regions may underlie the promotion and prevention systems and, therefore, may be activated when specific promotion or prevention goals are primed.

Semantic priming techniques have been used in numerous studies to activate idiographically assessed promotion and prevention goals, typically by presenting trait attributes that the individual had previously generated in a goal listing task (along with control attributes) and measuring the physiological, affective, and/or behavioral consequences (e.g., Strauman \& Higgins, 1987). Similar priming techniques have been used to study patterns of neural activation associated with the selfconcept, although usually with nomothetically determined priming stimuli. Using PET, Craik et al. (1999) presented subjects with a series of encoding tasks (including a self-referent encoding condition) based on a depth-of-processing model (Rogers, Kuiper, \& Kirker, 1977; Craik \& Tulving, 1975) and concluded that selfreferential information processing was functionally dissociable from other forms of semantic processing. Kelley et al. (2002) used event-related fMRI and found that a region of the medial prefrontal cortex (mPFC) was selectively engaged while participants processed selfreferential stimuli. Most recently, Heatherton et al. (2006) observed that the same mPFC activation distinguished judgments about self from judgments about intimate others.

We adapted the Kelley et al. (2002) fMRI procedure to include idiographically selected promotion and prevention goals within each participant's stimulus set in order to test whether priming promotion or prevention goals was associated with discrete patterns of cortical activation beyond that associated with self-referential processing per se. We predicted that promotion goal priming would be associated with left PFC activation and prevention goal priming would be associated with right PFC activation. We also anticipated that the patterns of brain activation previously reported in association with the depth-of-processing task would be observed, consistent with the view that social cognition is a complex, multilayered process within which self- regulation is embedded (Higgins, 1990). Furthermore, we explored the associations among prefrontal cortical activation in response to goal priming and measures of individual differences in regulatory focus and BIS/BAS sensitivity.

\section{METHODS}

\section{Overview}

Participants completed a self-descriptive questionnaire along with measures of individual differences in regulatory focus and BAS/BIS sensitivity and then, in a subsequent and ostensibly unrelated study, were imaged while making four types of judgments about positively valenced trait adjectives (listed in order of increasing depth of processing): syllable ("How many syllables does the word have?"), social desirability ("How socially desirable is it?"), other relevance ("How well does it describe Oprah Winfrey?"), and self-relevance ("How well does it describe you?'). Some of the trait adjectives were individual participants' promotion and prevention goals as obtained from their earlier questionnaire responses, whereas others were from a standard list or were the promotion or prevention goals of different participants. We sought to replicate previous findings regarding neural correlates of self-relevant processing by analyzing the judgment task data across all adjective types. We then examined whether incidental promotion and prevention goal priming were associated with distinct cortical activation patterns by analyzing the same data focusing on adjective type (i.e., the goal priming manipulation) and combining across the judgment tasks.

\section{Participants}

Participants were recruited through the introductory psychology research pool at Duke University and were part of a larger sample $(n=154)$ who had completed a study earlier in the semester described as an investigation of personality. Approximately 2 months later, individuals who had participated in the personality study were contacted by phone and recruited for what was described as an investigation of language processing. Eighteen students (11 men) agreed to participate; one withdrew from the study prior to completing the MRI session for medical reasons, and a second student's imaging data were unusable due to technical problems; thus, data from 16 participants were included in analyses. All participants were between the ages of 18 and 21 years and were righthanded as indicated by self-report. Participants reported normal neurological history and had normal or correctedto-normal visual acuity. All participants gave informed consent in accordance with IRB guidelines and received cash payment for participation. 


\section{Procedure}

Measures of Regulatory Focus and BIS/BAS Sensitivity

During the survey study, participants completed a battery of questionnaires, including a measure of regulatory focus and a measure of BIS and BAS sensitivity. The Regulatory Focus Questionnaire (RFQ; Higgins et al., 2001) is a 22-item Likert-style instrument designed to measure individual differences in orientation toward promotion and prevention goals. The RFQ contains four scales (two each for promotion and prevention): two bistory scales measuring the extent to which the individual's socialization history was characterized by an emphasis on promotion or prevention goals, and two success scales measuring the extent to which the individual believes she or he has been successful in attaining promotion or prevention goals. Sample items include: "My parents encouraged me to try new things" (promotion history); "My parents kept order in my house by having a lot of rules and regulations for me" (prevention history); "Experimenting with different kinds of classes has ignited interests in me that would not have developed otherwise" (promotion success); and "Not being careful enough has gotten me into trouble at times" (prevention success-reverse-scored). Higgins et al. (2001) reported that the success scales had internal consistency reliability (coefficient alpha) of .75 or higher, and a 2-month test-retest reliability (Pearson correlation) of .79 or higher. Psychometric data on the history scales have not yet been published.

The BIS/BAS Scale (BIS/BAS; Carver \& White, 1994) is a well-validated instrument containing four scales to measure individual differences in BAS and BIS sensitivity: BIS $(\alpha=.74)$, BAS reward responsiveness $(\alpha=.73)$, BAS drive $(\alpha=.76)$, and BAS fun-seeking $(\alpha=.66)$. In the current study, we report results for a general BAS principal component score combining all three BAS scales.

\section{Stimulus Generation}

During the survey study, participants also completed the Selves Questionnaire (SQ; Higgins, Bond, Klein, \& Strauman, 1986). The SQ is a semistructured measure that was used to sample participant's own promotion and prevention goals. Participants listed traits or attributes for different self-state representations (actual/own, ideal/ own, ideal/other, ought/own, and ought/other). Ideal self-beliefs are promotion goals, whereas ought selfbeliefs are prevention goals. The SQ was administered in two sections, the first involving the respondents' "own" standpoints (actual, ideal, and ought), and the second involving the standpoints of their parents (ideal and ought). On the first page of each section, the selfstate representations are defined. On each subsequent page, the participant is asked to list attributes pertaining to one of the self-state representations. For example, the participant is instructed to "Please list the attributes of the type of person you believe you actually are."

\section{Stimulus Selection}

Personal goal stimuli for the priming task were obtained from each participant's earlier responses to the SQ. Following the procedures used by Strauman (1996), four promotion goals ("ideal self" responses) and four prevention goals ("ought self" responses) that were semantically unrelated to each other were identified for each participant from among that participant's total set of SQ responses. All of the goals selected from participants' SQ responses were positively valenced. Then the promotion and prevention goals were pooled across subjects, and for each participant, a set of eight yoked-control words was selected from that pool so that each yoked-control word was semantically unrelated to all of the participant's promotion and prevention goals. Five words that had not been included in any participant's lists of personal goals (studious, literary, interested, regular, and outspoken) were used in practice trials for all participants.

\section{Priming Task}

Stimuli were presented in an event-related design over four blocks, each of which was 320 sec long and consisted of 21 trials (five practice words, four promotion goal primes, four prevention goal primes, and eight control primes), with the promotion, prevention, and control primes presented randomly within each block. Each word appeared for $2000 \mathrm{msec}$, with a fixation cross presented in the interstimulus interval (which varied randomly from 10 to $14 \mathrm{sec}$ ) to allow for the hemodynamic response to return to baseline. The practice words were presented first in each run so that participants could familiarize themselves with the response buttons and corresponding ratings. Stimuli were presented using CIGAL, an in-house data presentation software program (Voyvodic, 1999).

The depth-of-processing judgment task was adapted from that used by Kelley et al. (2002) and Craik et al. (1999). Depending on the block, participants were asked to indicate: (a) how many syllables the word had, (b) how socially desirable the trait was, (c) how well each of the trait words described Oprah Winfrey, or (d) how well each of the trait words described himself or herself. Response buttons for blocks (b) through (d) corresponded to the following ratings: not at all, a little, a lot, and extremely; response buttons for the syllables block corresponded to the numbers $2,3,4$, and 5 .

\section{MRI Scanning Procedures}

Images were acquired on a GE Signa 1.5-T scanner (Waukesha, Wisconsin). Functional T2*-weighted images 
sensitive to the blood-oxygenation-level-dependent (BOLD) contrast were acquired using a spiral gradientecho sequence $(\mathrm{TR}=2000 \mathrm{msec}, \mathrm{TE}=40 \mathrm{msec}$, flip angle $=90^{\circ}$, matrix $=64^{2}$; in-plane resolution $=$ $3.75 \mathrm{~mm}^{2}$ ). Scanning was event-related, and the functional imaging volume consisted of 28 contiguous 5-mm slices parallel to the line connecting the anterior and posterior commissures. Prior to functional acquisition, a T1-weighted structural set including a 28-slice image coplanar with the functionals was acquired for coregistration. Head motion was minimized by cushioning the participant's head and placing a strip of tape attached to the table across the participant's forehead. Stimuli were projected on a screen directly behind the participant's head within the scanner bore; participants viewed the screen with mirrored glasses. Responses were recorded using a response box placed under the participant's right hand.

\section{Data Analysis}

fMRI data were preprocessed and analyzed on a voxel-byvoxel basis using Statistical Parametric Mapping software (SPM2, Wellcome Department of Cognitive Neurology, London, UK; Friston et al., 1995). Functional data were corrected for differences in acquisition time between slices for each whole-brain volume, realigned within and across runs to correct for head movement, and coregistered with each participant's anatomical data. Functional data were transformed into a standard anatomical space based on the ICBM-152 brain template (Montreal Neurological Institute), and normalized data were then spatially smoothed with an 8-mm full-width half-maximum Gaussian filter.

Participants' event-related hemodynamic responses were convolved with a canonical hemodynamic response function. The effects of interest were estimated at every voxel using a general linear model, and movement parameters from realignment were included as effects of no interest. There were four event types: promotion goals, prevention goals, yoked control words, and practice words; and four judgment tasks varying in depth of processing. To replicate the Kelley et al. (2002) analyses involving judgment task effects, whole-brain statistical parametric maps (SPMs) of the $t$ statistic were generated for each participant for the linear contrasts of the events of interest (self and other judgments vs. number of syllables judgments, and self vs. other judgments).

For analyses involving promotion and prevention priming, whole-brain SPMs were generated for each participant for the linear contrasts of promotion versus prevention goal trials. Direct contrast of the experimental conditions is a conservative approach that ensures that the resulting activation patterns reflect only the differences between promotion and prevention goals (and not differences in self-relevance or stimulus source). These individual contrast images were then subjected to second-level (group) analyses with participants as random effects. SPMs for these analyses were thresholded for 5 or more contiguous voxels surviving $p<.01$ to search PFC areas and $p<.001$ for all other regions. Peak voxel coordinates were converted into Talairach space (Talairach \& Tournoux, 1988) using the Talairach Daemon (Lancaster et al., 2000).

\section{RESULTS}

\section{Neural Activation Associated with Judgment Tasks}

Before considering whether promotion or prevention goal priming was associated with specific activation patterns, we sought to determine whether the participants manifested task-related activation patterns similar to those observed previously. We examined activation patterns associated with the four judgment tasks by collapsing across the three stimulus types (promotion goal primes, prevention goal primes, and control primes) as analyzed by Kelley et al. (2002). First, we compared the self and other trials with the syllables trials. Kelley et al. had reported that the self and other trials, relative to trials in which participants were asked whether stimuli were printed in lower or upper case, were associated with increased activation in the left inferior frontal cortex (peak voxel, $x=-42, y=16, z=4$ ) and anterior cingulate (peak voxel, $x=0, y=14, z=42$ ). In the present study, the self and other trials (relative to the "syllables" trials) also were associated with increased activation in the anterior cingulate and in the left inferior frontal cortex. For this comparison, we also observed a large area of significant activation in the $\mathrm{mPFC}$ and in the bilateral inferior parietal cortex. Peak locations for activated regions are listed in Table 1.

We then compared the self-referent block with the other-referent block, again collapsing across stimulus type. Kelley et al. (2002) had reported that relative to the other-referent trials, the self-referent trials were associated with increased activation in the MPFC (peak voxel, $x=10, y=52, z=2$ ) and posterior cingulate (peak voxel, $x=12, y=-48, z=50$ ). In the present study, self judgments (relative to other judgments) also were associated with activation in the MPFC and posterior cingulate, as well as the right superior frontal gyrus, bilateral superior temporal gyrus, and left insula/ superior temporal gyrus (see Table 1).

\section{Neural Activation following Promotion Goal Priming}

To test the hypothesis that priming promotion goals leads to activation in regions of the left PFC, we compared trials in which one of the participant's promotion goals was presented with trials in which a prevention goal was presented (combining across the four judgment tasks). Compared to prevention priming, promotion goal priming was associated with significant 
Table 1. Peak Locations for Activated Regions Associated with Judgment Type

\begin{tabular}{|c|c|c|c|c|c|c|}
\hline \multirow[b]{2}{*}{ Brain Region } & \multirow[b]{2}{*}{$B A$} & \multicolumn{3}{|c|}{ Talairach Coordinates } & \multirow[b]{2}{*}{ Z Score } & \multirow[b]{2}{*}{ Puncorrected } \\
\hline & & $x$ & $y$ & $z$ & & \\
\hline \multicolumn{7}{|l|}{ Self/Other versus Syllable } \\
\hline Anterior cingulate & 24 & -3 & 30 & 15 & 3.13 & $<.01$ \\
\hline Left inferior frontal cortex & 47 & -48 & 23 & -12 & 6.44 & $<.001$ \\
\hline Medial prefrontal cortex & $9 / 10$ & 3 & 54 & 31 & 7.41 & $<.001$ \\
\hline Left inferior parietal lobe & 39 & -48 & -60 & 32 & 5.94 & $<.001$ \\
\hline Right inferior parietal lobe & 40 & 42 & -54 & 32 & 5.02 & $<.001$ \\
\hline \multicolumn{7}{|l|}{ Self versus Other } \\
\hline Posterior cingulate gyrus & 30 & -18 & -52 & 11 & 4.76 & $<.001$ \\
\hline Medial prefrontal cortex & $8 / 9$ & 0 & 42 & 31 & 4.13 & $<.001$ \\
\hline Right superior frontal gyrus & 6 & 30 & 0 & 63 & 5.99 & $<.001$ \\
\hline Left superior temporal gyrus & $41 / 42$ & -48 & -26 & 1 & 4.72 & $<.001$ \\
\hline Right superior temporal gyrus & $41 / 42$ & 45 & -24 & 0 & 4.83 & $<.001$ \\
\hline Left insula & & -33 & 6 & -4 & 4.56 & $<.001$ \\
\hline
\end{tabular}
location.

activation in the bilateral orbital PFC (see Figure 1) and the left parahippocampal gyrus. Peak locations for activated regions associated with the goal priming conditions are listed in Table 2.

To examine more closely the bilateral prefrontal activation associated with promotion goal priming, we extracted percent signal change data from the two clusters identified in the contrast analysis by selectively averaging the signal change (relative to a prestimulus baseline) separately for the promotion and prevention goal trials (see Figure 2). Compared to the other three conditions (averaged at 8-12 sec following stimulus onset), the neural response to promotion priming in the left PFC was significantly stronger $[t(14)=2.24, p<.05]$.

\section{Neural Activation following Prevention Goal Priming}

To test the hypothesis that priming prevention goals leads to activation in the right PFC, we compared activation following trials in which one of the participant's prevention goals was presented with activation following trials in a promotion goal was presented (combining across the four judgment tasks/blocks). We observed that compared to promotion goal priming, prevention goal priming was only associated with activation in the anterior cingulate cortex. The peak location for this activation is listed in Table 2.

\section{Correlations of Peak Activations with Measures of Regulatory Focus and BIS/BAS Sensitivity}

To examine the relationships between neural activation associated with promotion goal priming and individual differences in regulatory focus and BAS/BIS sensitivity, we again extracted the MR data from the two functionally defined prefrontal regions. We computed each participant's percent MR signal change from baseline using all voxels in the functionally defined regions that were significant at the level of the group analysis at $p<.001$, averaged across all 16 promotion goal priming trials and averaged across the peak time points (8-12 sec following stimulus onset) for the promotion goal priming trials. We then conducted zero-order correlation analyses with participants' RFQ and BIS/BAS scale scores, the results of which are shown in Table 3.

Magnitude of activation in the left PFC region was significantly correlated with RFQ promotion success scores $(r=.63, p<.05)$, and the correlation with promotion history approached significance $(r=.43$, $p<.10)$. Figure 2 shows the scatterplot of individual data points for the correlation between left PFC activation and promotion success scores. For the right PFC region, we removed one outlier whose percent signal change data were 4 standard deviations above the mean of the remaining 15 subjects. After removing the outlier, we observed that magnitude of activation in the right PFC region was significantly correlated only with BIS 
Figure 1. Image highlighting regional cerebral blood flow changes in the orbital prefrontal cortex associated with the contrast of promotion versus prevention goal priming. The graphs show the time course of the percent signal change from baseline in the left PFC and right PFC sites for both promotion (blue lines) and prevention (red lines) goal priming trials. Image shown in neurological convention.

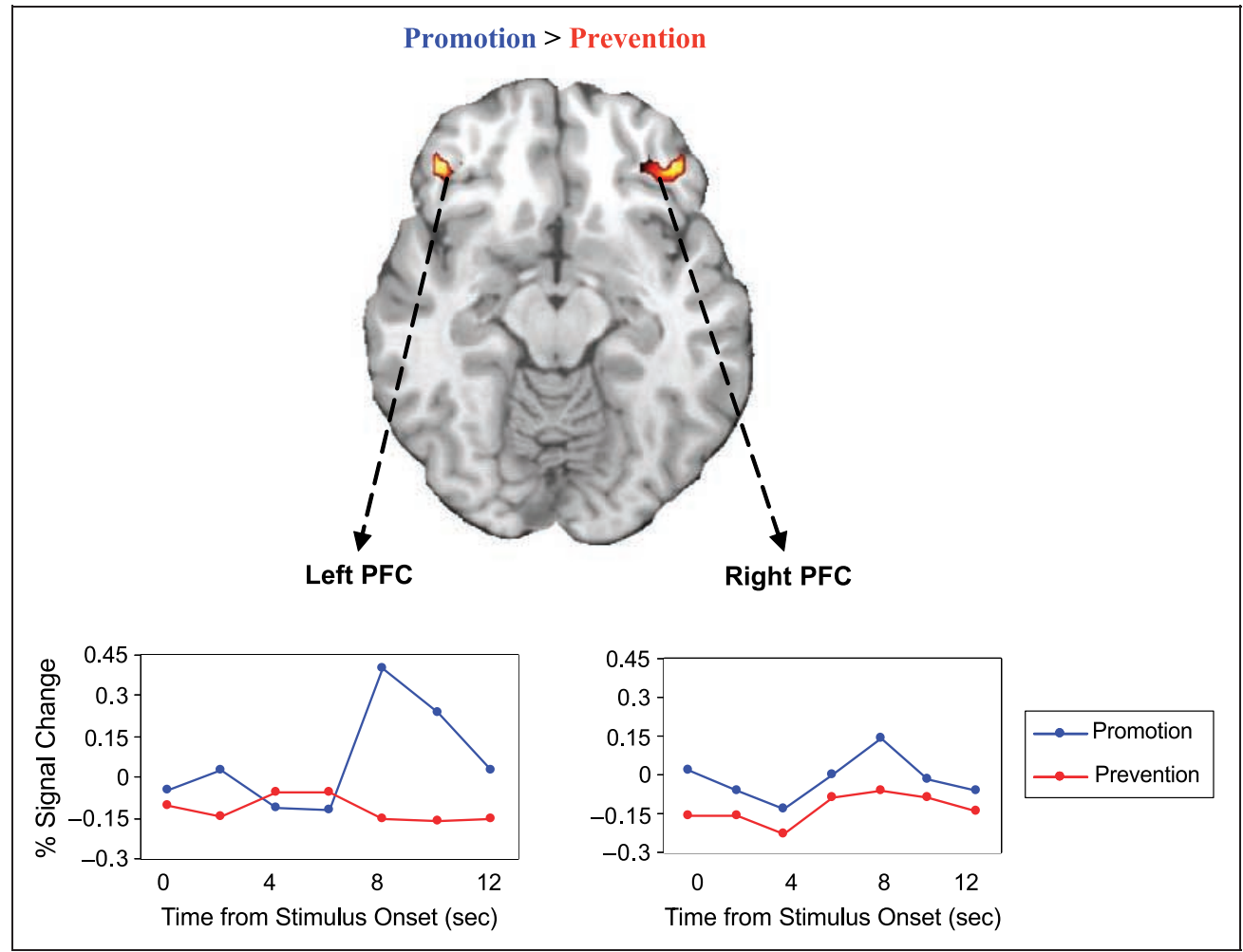

scale scores. None of the correlations with the RFQ or BAS scales was significant.

\section{DISCUSSION}

As representations of desired states, goals are critical constructs within social-cognitive theories of motivation. RFT postulates two types of goals: promotion goals, which involve attaining positive outcomes by "making good things happen," and prevention goals, which involve attaining positive outcomes by "keeping bad things from happening." Although there has been extensive research testing the behavioral predictions of RFT, the neural correlates of promotion and prevention goal activation had not been explored. To our knowledge, the present study is the first to document differences in neural activation between promotion goal and prevention goal priming, and the first to demonstrate that the neurophysiological correlates of personal goal priming could be observed even as participants were engaged in a task not directly relevant to the content of their goals.

The design of this study allowed us to examine two putatively orthogonal cognitive processes that we predicted would be occurring simultaneously within the same experimental task. The judgment task required

Table 2. Peak Locations for Activated Regions following Promotion and Prevention Goal Priming

\begin{tabular}{|c|c|c|c|c|c|c|}
\hline \multirow[b]{2}{*}{ Brain Region } & \multirow[b]{2}{*}{$B A$} & \multicolumn{3}{|c|}{ Talairach Coordinates } & \multirow[b]{2}{*}{ Z Score } & \multirow[b]{2}{*}{ puncorrected } \\
\hline & & $x$ & $y$ & $z$ & & \\
\hline \multicolumn{7}{|l|}{ Promotion Goal Priming } \\
\hline Left orbital prefrontal cortex & $11 / 47$ & -36 & 40 & -17 & 3.70 & $<.001$ \\
\hline Right orbital prefrontal cortex & $11 / 47$ & 45 & 34 & -17 & 3.34 & $<.001$ \\
\hline Right parahippocampal gyrus & $36 / 28$ & 27 & -6 & -11 & 5.11 & $<.001$ \\
\hline \multicolumn{7}{|l|}{ Prevention Goal Priming } \\
\hline Anterior cingulate & 32 & 9 & 29 & -1 & 3.79 & $<.001$ \\
\hline
\end{tabular}




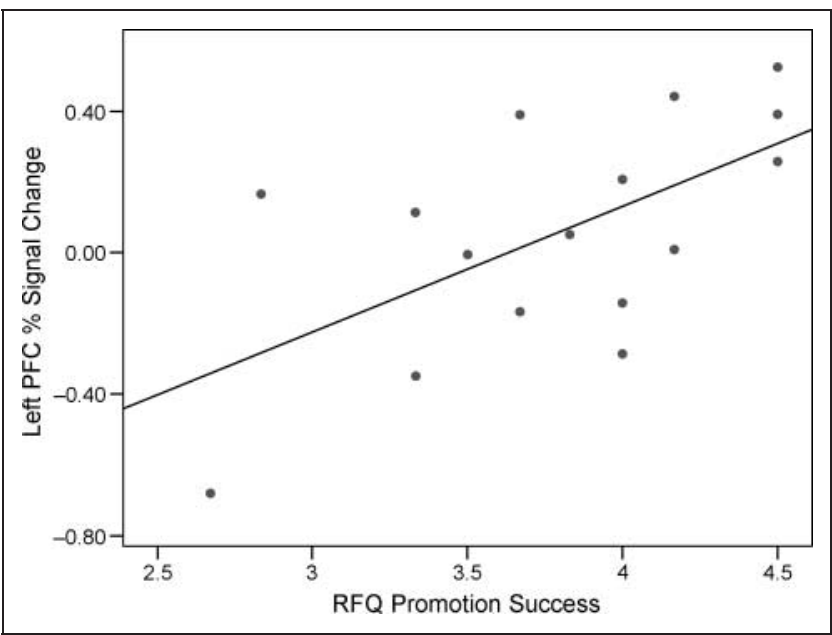

Figure 2. Scatterplot with regression line showing the correlation between RFQ promotion success scores and percent signal change in the left PFC for the promotion priming condition.

subjects to evaluate trait adjectives on the basis of both semantic and nonsemantic criteria. We found substantial overlap between the neural activation patterns reported by Kelley et al.'s (2002) comparisons of depthof-processing levels and those observed in the present study when we compared participants' responses across the priming blocks. This overlap indicates that our participants were responding to the judgment task in a manner consistent with those in the study of Kelley et al. Just as importantly, the findings allow us to determine whether neural activation following personal goal priming can be distinguished from activation associated with selfreferential information processing per se-a distinction that would be consistent with both depth-of-processing models and social-cognitive theories of motivation such as RFT.

To examine the neural activation consequences of promotion and prevention goal priming, we embedded each participant's idiographically assessed goals within the experimental task to test the prediction that priming promotion and prevention goals would be associated with neural activation in the left and right $\mathrm{PFC}$, respectively. Only two studies had examined associations between regulatory focus and cortical activation: the rest- ing EEG study by Amodio et al. (2004) and the fMRI/ judgments-about-concepts study by Cunningham et al. (2005). Our hypotheses were based primarily on inferences from previous research showing that left prefrontal/ frontal activation was associated with approach tendencies and positive affectivity, whereas right prefrontal/ frontal activation was associated with avoidance tendencies and negative affectivity.

Consistent with our prediction, promotion goal priming (but not prevention goal priming) was associated with activation in the left orbital PFC. The magnitude of activation in this area was positively correlated with scores on the RFQ promotion success subscale and, to a lesser degree, the promotion history subscale. We note that the orbito-frontal cortex has been implicated in reward processing (Kringelbach, 2005), and this region also may be involved in evaluation of the motivational significance of stimuli and other higher-level cognitive aspects of goal-directed behavior (Hollerman, Tremblay, \& Schultz, 2000). Thus, one interpretation of this finding is that incidental exposure to promotion goals activates goal representations involving pursuit of positive outcomes by "making good things happen," and that this activation is particularly robust for individuals with a chronically strong orientation to promotion goals-an interpretation entirely consistent with RFT. In addition, findings from behavioral studies of individual differences in regulatory focus have indicated that individuals with a chronic focus on promotion goals are characterized by a broad "world view" (Kelly, 1955) that casts social interactions in promotion terms. Such a cognitive style, as it might be described, implies an abstract, top-down influence on social cognition that is consistent with current theorizing about the function of the anterior/orbital PFC (e.g., Ramnani \& Owen, 2004; Miller \& Cohen, 2001).

We also found that promotion goal priming activated an area within the right orbital PFC. However, magnitude of activation in this area was not associated with regulatory focus, but only with individual differences in BIS sensitivity, an observation consistent with prior studies of BAS/BIS and cortical asymmetries in dispositional affectivity. Such right PFC activation in response to promotion goal priming may reflect a characteristic tendency among individuals with high BIS toward right PFC activation in the context of exposure to goal-related

Table 3. Correlations among Questionnaire Measures and Percent MR Signal Change in Prefrontal Cortex following Promotion Goal Priming

\begin{tabular}{lcccrrr}
\hline & Promotion History & Promotion Success & Prevention History & Prevention Success & BIS & BAS \\
\hline Left PFC & .43 & $.63^{*}$ & .32 & .27 & -.13 \\
Right PFC & -.08 & .15 & .24 & -.16 & .10 \\
\hline
\end{tabular}

$n=16$.

$* p<.05$. 
cues broadly defined. The fact that a similar pattern of activation was not found for prevention goal priming may be due to differences in the relative salience of the goal classes for this student sample. Furthermore, it is possible that personally salient goal cues may simultaneously activate cognitive processes that support promotion-related (e.g., eagerness to achieve the goal) and prevention-related (e.g., fear of failure to reach the goal) strategies.

It is interesting to note that the left orbital PFC activation uniquely associated with promotion goals occurred at the same time participants were engaged in judgment tasks with no obvious relevance to either approach/avoidance tendencies or personal goal pursuit. That is, incidental exposure to promotion and prevention goals led to neural activation patterns distinguishable from each other as well as from the activation associated with the tasks themselves. The present data parallel those from previous studies in which incidental exposure to the two kinds of goals led to reliably distinguishable behavioral, affective, and physiological consequences without participants' awareness or intent (e.g., Strauman \& Higgins, 1987). Our findings illustrate both the complexity of social cognition and the ubiquitous nature of selfregulation: even as participants were engaged in the judgment tasks, a discriminant pattern of neural activation associated with incidental exposure to promotion goals was detectable. The direct comparison of promotion and prevention conditions allowed us to rule out the alternative hypothesis that the activation patterns associated with either condition merely reflected the impact of self-relevant stimuli or of priming goal representations per se.

Although the left PFC area activated during promotion goal priming overlaps with the reward circuit, other brain areas typically thought to be part of this circuit, such as the amygdala or nucleus accumbens (O'Doherty, 2004), were not activated in either goal priming condition. In retrospect, this was not surprising because the stimuli used in previous studies were either pictures intended to elicit basic emotional states or were tangible rewards available to participants (e.g., money). Such "primary inducers" (Phan et al., 2004) have intrinsic, evolutionarily determined reinforcement value, whereas the trait attributes used as goal primes have idiosyncratic, symbolic value as higher-order goals within a complex goal hierarchy (Carver \& Scheier, 1998). Priming individuals' promotion goals selectively engaged brain regions that support planning and behavior for "making good things happen" (Higgins, 1997), but did not selectively engage either reward or fear circuitry per se. If accurate, this conclusion supports the contention that promotion and prevention are neither identical to nor reducible to BAS/BIS.

For prevention goal priming, our prediction of unique right PFC activation was not confirmed. One possible explanation reflects the characteristics of the sample.
Undergraduate students at a highly selective university may be preferentially oriented toward approach-type goals. Indeed, in both the sample who participated in the imaging study $(n=16)$ and the larger sample from which they were recruited $(n=154)$, scores on the RFQ promotion success subscale were significantly higher than on the prevention success subscale (for the smaller sample, means $=3.79$ vs. 3.39, respectively, $p<.05$; for the larger sample, means $=3.83$ vs. 3.42 respectively, $p<.001)$. Therefore, promotion goals may have been more personally significant, and therefore, more salient, to these students. A second possibility is that the neural pathways underlying avoidance may be activated more effectively via exposure to cues related to the feared self (Carver, Lawrence, \& Scheier, 1999), a concept distinct from the "ought" self (from which prevention goal primes were obtained). Because trait attributes on the basis of one's feared self would be negatively valenced (introducing a potential confound in the study), a different design would be needed to determine whether priming with idiographic feared-self attributes engaged brain mechanisms associated with behavioral avoidance.

Another possible explanation for the weak findings with prevention goal priming entails the greater complexity of prevention compared to promotion. Whereas research on the developmental origins of promotion and prevention (e.g., Manian, Papadakis, Strauman, \& Essex, 2006) indicates that individual differences in the strength of promotion goals result from nurturant parenting, individual differences in prevention reflect two distinct kinds of parenting: punishment, which would be likely to engage the fear system, and an emphasis on rules, which would be more likely to engage brain regions associated with conscience (e.g., Greene, Somerville, Nystrom, Darley, \& Cohen, 2001). If participants' prevention goals were derived from a combination of these two distinct pathways, then it would be difficult to detect a single characteristic pattern of brain activation following prevention priming. However, additional research with greater statistical power and a more fine-grained assessment of participants' prevention goals would be needed to test this alternative hypothesis.

It is worth noting that the findings for promotion goal priming were both robust and consistent with our hypotheses although we used an idiographic approach to assess personal goals. In fact, the semistructured questionnaire used to help participants generate "ideal" and "ought" self-descriptors presumes that individuals will tend to generate those goals that are most highly chronically accessible for them (Higgins, 1990). This approach allowed us to test such an accessibility-based model of self-regulation and to demonstrate that promotion and prevention goals, despite varying from one person to another in terms of content, differ systematically across individuals in their neural substrates.

This article began with two observations, the motivational significance of personal goals and the complexity of 
social cognition, and proposed that functional neuroimaging would be useful for exploring them individually and jointly. In this study, we found preliminary evidence that even while participants were engaged in a judgment task with no relevance to personal goals or approach/ avoidance motivation, there was evidence for promotiongoal-specific activation following incidental priming of such goals. By combining idiographic assessment of goals with semantic priming, we demonstrated that promotion goals uniquely activate an area of the brain previously found to be associated with dispositional approach tendencies as well as goal pursuit behaviors even as participants made judgments about the stimuli that were irrelevant to the attributes' self-regulatory significance. As knowledge about the interface of social cognition, motivation, and neurophysiology increases, we anticipate being better able to identify how cognitive and motivational systems at different levels of analysis can account for individual differences in behavior, affect, and development.

\section{Acknowledgments}

We thank Amy Noll McLean, Dana Torpey, and Lori Kwapil for their expert assistance with data collection and technical support. The research was supported by National Institute of Mental Health grants 045800 and 067447 and by National Science Foundation grant 0106905.

Reprint requests should be sent to Kari M. Eddington, Department of Psychology and Neuroscience, Duke University, Box 90085, 9 Flowers Drive, Durham, NC 27708, or via e-mail: kari.eddington@duke.edu.

\section{REFERENCES}

Allen, J. J. B., \& Kline, J. P. (2004). Editorial: Frontal EEG asymmetry, emotion, and psychopathology: The first, and the next 25 years. Biological Psychology, 67, 1-5.

Amodio, D. M., Shah, J. Y., Sigelman, J., Brazy, P. C., \& Harmon-Jones, E. (2004). Implicit regulatory focus associated with asymmetrical frontal cortical activity. Journal of Experimental Social Psychology, 40, 225-232.

Andersen, S. M., \& Chen, S. (2002). The relational self: An interpersonal social-cognitive theory. Psychological Review, 109, 619-645.

Austin, J. T., \& Vancouver, J. B. (1996). Goal constructs in psychology: Structure, process, and content. Psychological Bulletin, 120, 338-375.

Bandura, A. (1986). Social foundations of thought and action: A social cognitive theory. Englewood Cliffs, NJ: Prentice-Hall.

Canli, T., Desmond, J. E., Zhao, Z., Glover, J. E., \& Gabrieli, J. D. E. (1998). Hemispheric asymmetry for emotional stimuli detected with fMRI. NeuroReport, 9, 3233-3239.

Carver, C. S., Lawrence, J. W., \& Scheier, M. F. (1999). Self-discrepancies and affect: Incorporating the role of feared selves. Personality and Social Psychology Bulletin, 25, 783-792.

Carver, C. S., \& Scheier, M. F. (1998). On the self-regulation of behavior. New York: Cambridge University Press.
Carver, C. S., \& White, T. L. (1994). Behavioral inhibition, behavioral activation, and affective responses to impending reward and punishment. The BIS/BAS Scales. Journal of Personality and Social Psychology, 67, 319-333.

Cervone, D. (2000). Evolutionary psychology and explanation in personality psychology. American Behavioral Scientist, 43, 1001-1014.

Coan, J. A., \& Allen, J. J. (2003). Frontal EEG asymmetry and the behavioral activation and inhibition systems. Psychophysiology, 40, 106-114.

Craik, F. I. M., Moroz, T., Moscovitch, M., Stuss, D., Winocur, G., Tulving, E., et al. (1999). In search of the self: A positron emission tomography study. Psychological Science, 10, 26-34.

Craik, F. I. M., \& Tulving, E. (1975). Depth of processing and the retention of words in episodic memory. Journal of Experimental Psychology: General, 104, 268-294.

Cunningham, W. A., Raye, C. L., \& Johnson, M. K. (2005). Neural correlates of evaluation associated with promotion and prevention regulatory focus. Cognitive, Behavioral, and Affective Neuroscience, 5, 202-211.

Davidson, R. J. (2004). Commentary: What does the prefrontal cortex "do" in affect? Perspectives on frontal EEG asymmetry research. Biological Psychology, 67, 219-233.

Davidson, R. J., \& Irwin, W. (1999). The functional neuroanatomy of emotion and affective style. Trends in Cognitive Sciences, 3, 11-21.

Depue, R. A., \& Collins, P. F. (1999). Neurobiology of the structure of personality: Dopamine, facilitation of incentive motivation, and extraversion. Behavioral and Brain Sciences, 22, 491-569.

Depue, R. A., \& Iacono, W. G. (1989). Neurobehavioral aspects of affective disorders. Annual Review of Psychology, 40, 457-492.

Dolcos, F., LaBar, K. S., \& Cabeza, R. (2004). Dissociable effects of arousal and valence on prefrontal activity indexing emotional evaluation and subsequent memory: An event-related fMRI study. Neuroimage, 23, 64-74.

Fowles, D. C. (1988). Psychophysiology and psychopathology: A motivational approach. Psychophysiology, 25, 373-391.

Fowles, D. C. (1994). A motivational theory of psychopathology. In W. Spaulding (Ed.), Integrative views of motivation, cognition, and emotion. Nebraska symposium on motivation (Vol. 41, pp. 181-238). Lincoln: University of Nebraska Press.

Friston, K., Ashburner, J., Firth, C., Poline, J., Heather, J., \& Frackowiak, R. (1995). Spatial registration and normalization of images. Human Brain Mapping, 2, 165-189.

Gray, J. A. (1982). The neuropsychology of anxiety: An enquiry into the functions of the septo-hippocampal system. New York: Oxford University Press.

Gray, J. A. (1990). Brain systems that mediate both emotion and cognition. Cognition and Emotion, 4, 269-288.

Greene, J., Somerville, R., Nystrom, L., Darley, J., \& Cohen, J. (2001). An fMRI investigation of emotional engagement in moral judgment. Science, 293, 2105-2108.

Harmon-Jones, E., \& Allen, J. B. (1997). Behavioral activation sensitivity and resting frontal EEG asymmetry: Covariation of putative indicators related to risk for mood disorders. Journal of Abnormal Psychology, 106, 159-163.

Heatherton, T. F., Wyland, C. L., Macrae, C. N., Demos, K. E., Denny, B. T., \& Kelley, W. M. (2006). Medial prefrontal activity differentiates self from close others. Social, Cognitive, and Affective Neuroscience, 1, 18-25.

Higgins, E. T. (1987). Self-discrepancy: A theory relating self and affect. Psychological Review, 94, 319-340.

Higgins, E. T. (1990). Personality, social psychology, and person-situation relations: Standards and knowledge 
activation as a common language. In L. A. Pervin (Ed.), Handbook of personality: Theory and research (pp. 301-338). New York: Guilford Press.

Higgins, E. T. (1997). Beyond pleasure and pain. American Psychologist, 52, 1280-1300.

Higgins, E. T., Bond, R. N., Klein, R., \& Strauman, T. (1986). Self-discrepancies and emotional vulnerability: How magnitude, accessibility, and type of discrepancy influence affect. Journal of Personality and Social Psychology, 51, $5-15$.

Higgins, E. T., Friedman, R. S., Harlow, R. E., Idson, L., Ayduk, O., \& Taylor, A. (2001). Achievement orientations from subjective histories of success: Promotion pride versus prevention pride. European Journal of Social Psychology, 31, 3-23.

Higgins, E. T., \& Spiegel, S. (2004). Promotion and prevention strategies for self-regulation: A motivated cognition perspective. In R. F. Baumeister \& K. D. Vohs (Eds.), Handbook of self-regulation: Research, theory, and applications (pp. 171-187). New York: Guilford Press.

Hollerman, J. R., Tremblay, L., \& Schultz, W. (2000). Involvement of basal ganglia and orbitofrontal cortex in goal-directed behavior. Progress in Brain Research, 126, 193-215.

Karoly, P. (1993). Mechanisms of self-regulation: A systems view. Annual Review of Psychology, 44, 23-52.

Kelley, W. M., Macrae, C. N., Wyland, C. L., Caglar, S., Inati, S., \& Heatherton, T. F. (2002). Finding the self? An eventrelated fMRI study. Journal of Cognitive Neuroscience, 14, 785-794.

Kelly, G. A. (1955). The psychology of personal constructs. Vol. 1: A theory of personality. New York: Norton.

Kringelbach, M. L. (2005). The human orbitofrontal cortex: Linking reward to hedonic experience. Nature Reviews Neuroscience, 6, 691-702.

Lancaster, J. L., Woldorff, M. G., Parsons, L. M., Liotti, M., Freitas, C. S., Rainey, L., et al. (2000). Automated Talairach atlas labels for functional brain mapping. Human Brain Mapping, 10, 120-131.

Manian, N., Papadakis, A. M., Strauman, T. J., \& Essex, M. (2006). The development of children's ideal and ought self-guides: The influence of parenting on individual differences in guide strength. Journal of Personality, 74, $1619-1645$.

Miller, E. K., \& Cohen, J. D. (2001). An integrative theory of prefrontal cortex function. Annual Review of Neuroscience, 24, 167-202.

Mischel, W. (1990). Personality dispositions revisited and revised: A view after three decades. In L. Pervin (Ed.),
Handbook of personality: Theory and research (pp. 111-134). New York: Guilford.

O'Doherty, J. P. (2004). Reward representations and reward-related learning in the human brain: Insights from neuroimaging. Current Opinion in Neurobiology, 14, 769-776.

Phan, K. L., Taylor, S. F., Welsh, R. C., Ho, S., Britton, J. C., \& Liberzon, I. (2004). Neural correlates of individual ratings of emotional salience: A trial-related fMRI study.

Neuroimage, 21, 768-780

Ramnani, N., \& Owen, A. M. (2004). Anterior prefrontal cortex: Insights into function from anatomy and neuroimaging. Nature Reviews Neuroscience, 5, 184-194.

Rogers, T. B., Kuiper, N. A., \& Kirker, W. S. (1977). Self-reference and the encoding of personal information. Journal of Personality and Social Psychology, 35, 677-688.

Smith, E. R., \& Semin, G. R. (2004). Socially situated cognition: Cognition in its social context. In M. P. Zanna (Ed.), Advances in experimental social psychology (Vol. 36, pp. 53-117). San Diego, CA: Elsevier Academic Press.

Strauman, T. J. (1996). Stability within the self: A longitudinal study of the implications of self-discrepancy theory. Journal of Personality and Social Psychology, 71, 1142-1153.

Strauman, T. J. (2002). Self-regulation and depression. Self and Identity, 1, 151-157.

Strauman, T. J., \& Higgins, E. T. (1987). Automatic activation of self-discrepancies and emotional syndromes: When cognitive structures influence affect. Journal of Personality and Social Psychology, 53, 1004-1014.

Sutton, S., \& Davidson, R. (1997). Prefrontal brain asymmetry: A biological substrate of the behavioral approach and inhibition systems. Psychological Science, 8, 204-210.

Talairach, J., \& Tournoux, P. (1988). Co-planar stereotaxic atlas of the buman brain. Stuttgart, Germany: Georg Thierne Verlag.

Tanner, W. P., Jr., \& Swets, J. A. (1954). A decision-making theory of visual detection. Psychological Review, 61, 401-409.

Tomarken, A. J., \& Keener, A. D. (1998). Frontal brain asymmetry and depression: A self-regulatory perspective. Cognition and Emotion, 12, 387-420.

Voyvodic, J. T. (1999). Real-time fMRI paradigm control, physiology, and behavior combined with near real-time statistical analysis. Neuroimage, 10, 91-106.

Watson, D., Wiese, D., Vaidya, J., \& Tellegen, A. (1999). The two general activation systems of affect: Structural findings, evolutionary considerations, and psychobiological evidence. Journal of Personality and Social Psychology, 76, $820-838$. 